\title{
LCI699 is a Potent Inhibitor of Cortisol Production in Vitro
}

\section{Aim}

To compare the in vitro effects of LCI699, metyrapone, and ketoconazole on cortisol production and steroid hormone profile in human adrenal cells

\section{Introduction}

- Ketoconazole and metyrapone are frequently used steroidogenesis inhibitors for treatment of Cushing's syndrome (CS)

- LCl699 (Osilodrostat) is a new steroidogenesis inhibitor which is known to block 11ß-hydroxylase

-This compound was originally developed for its inhibitory effects on aldosterone production, but appeared to decrease cortisol response to ACTH-stimulation in patients with hypertension

- LCI699 is now investigated as a potential drug for treatment of CS, but effects on other steroidogenesis enzymes are unknown

\section{Results}

1. Effects of LCI699, metyrapone, and ketoconazole on cortisol production in HAC-15 cells

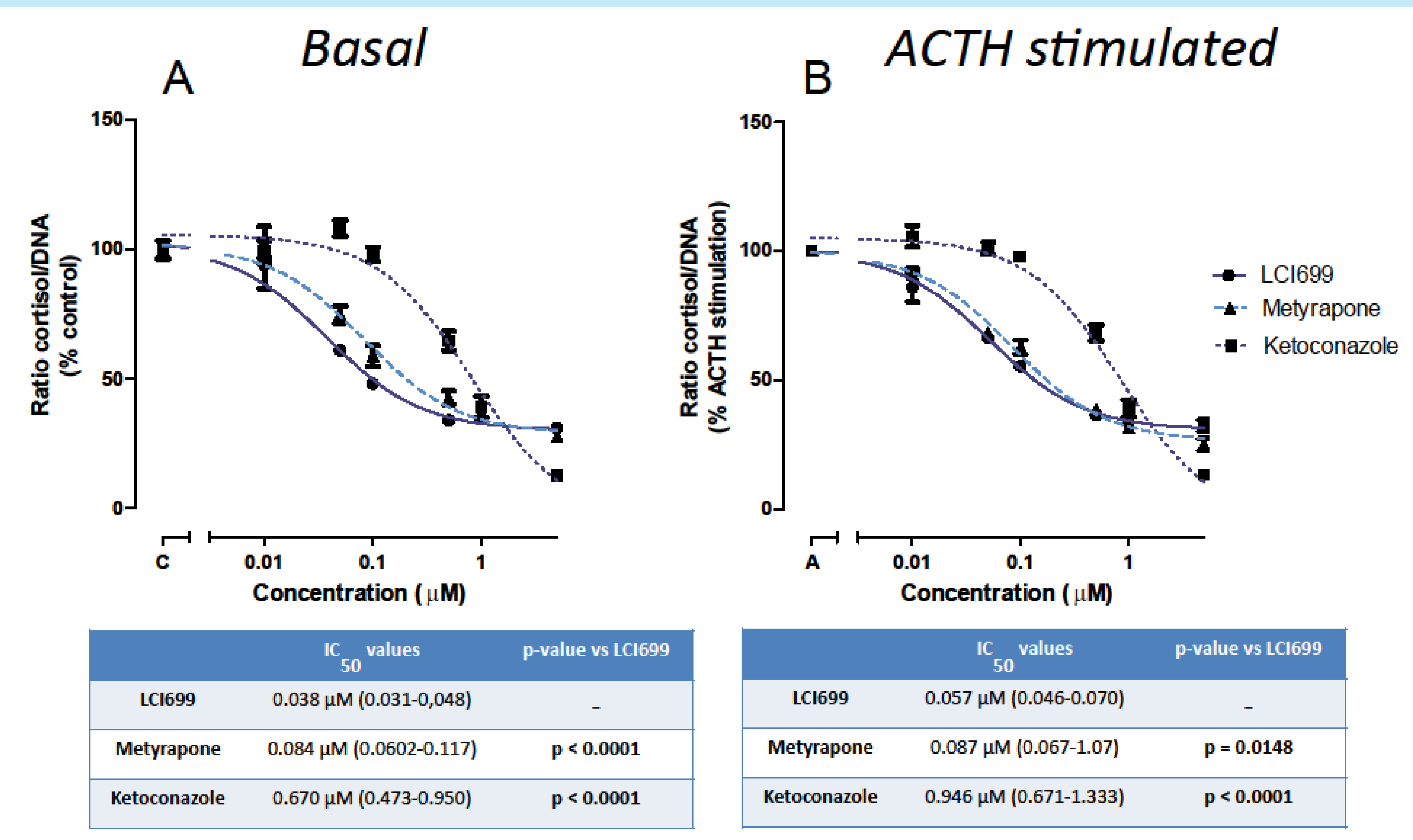

Figure 1. Effects of LCI699, metyrapone, and ketoconazole on cortisol production in HAC-15 cells under basal conditions (A) and when stimulated with $10 \mathrm{nM}$ ACTH, corrected for cell amount. In the right graph, ACTH stimulation is set as $100 \%$. Cortisol is measured using chemiluminescence immunoassay system. $I C$ values represent the half maximal inhibitory concentration. Data are indicated as mean SEM. C, control; A, ACTH.

\section{Effects of LCI699, metyrapone, and ketoconazole on the steroid profile in HAC-15 cells}

primary adrenocortical adenoma cultures

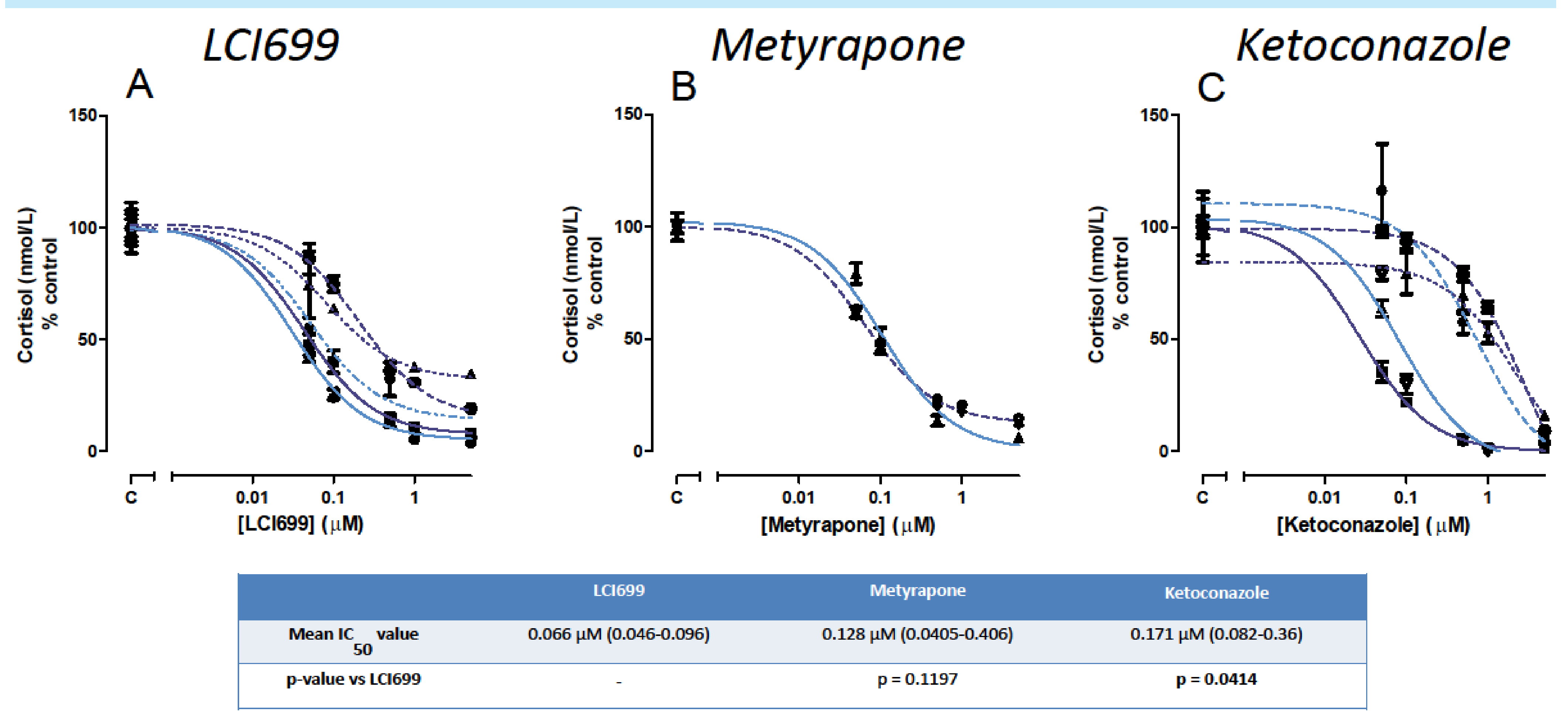

Figure 2. Effects of LCl699 (A), metyrapone (B), and ketoconazole (C) on cortisol production in primary adrenocortical adenoma cultures. Cortisol is measured using a chemiluminescence immunoassay system. Same layout of the lines in the different figures corresponds to the same patient. Mean IC values represent the mean half maximal inhibitory concentration of all primary cultures. Data are indicated as mean + SEM. C, control.

\section{Conclusions}

- LCl699 is a potent inhibitor of basal- and ACTH-stimulated cortisol production in adrenocortical tumor cells (to block 11ß-hydroxylase (CYP11B1), and to The absence of strong accumulation of steroid precursors might indicate an inhibition proximal of $3 \beta-H S D$

$\begin{array}{ll}\underset{\text { University Medical center Rotterdam }}{\text { Erasmost: }} & \begin{array}{l}\text { Contact } \\ \text { s.creemers@erasmusmc.nl } \\ \text { or scan QR code }\end{array}\end{array}$

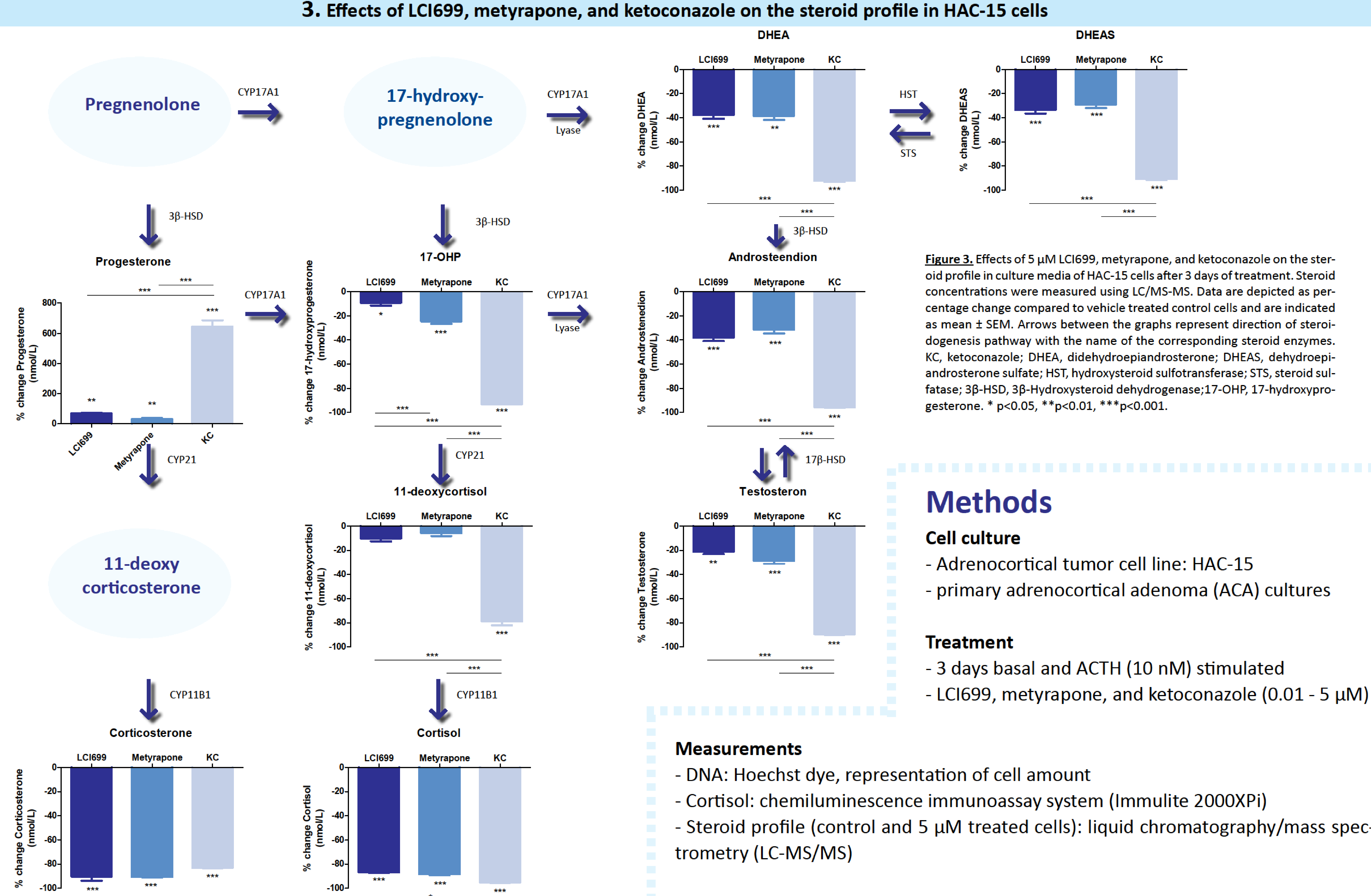

